\title{
Reflectivity of HIVIAIDS Survivors as Risk Society in Dealing with Medical Risk
}

\author{
Argyo Demartoto, ${ }^{1, *}$, Bhisma Murti $^{2}$, and Siti Zunariyah ${ }^{1}$ \\ ${ }^{1}$ Department of Sociology, Sebelas Maret University, Surakarta, Indonesia \\ 2 Department of Public Health, Sebelas Maret University, Surakarta, Indonesia
}

\begin{abstract}
People Living with HIV/AIDS (PLWHA) are associated with death, but this study disagrees with such social construction. This qualitative research with phenomenological approach aimed to analyze the reflectivity of HIV/AIDS survivors in dealing with medical risk in Surakarta, Indonesia, using observation, in-depth interview, medical record, and viral load test and supported with information obtained from the informants analyzed using Beck's risk society theory. Result showed HIV/AIDS survivors undertook a healthy life and kept surviving because they performed reflexive modernization on medical risk. Some PLWHAs encountered side effects of ARV therapy. CD4 level of 50/ml led to blackish skin and itchiness, but after 3-month ARV therapy, the blackish skin disappeared. Some PLWHAs always developed morning sickness, itchiness and skin reddishness due to abacavir consumption. To avoid it, they consume liquid food like juice or milk. Steve-Johnson's Syndrome occurred in the first week during ARV consumption on average. Opened communication, information, and nutrition counseling are very desirable. ARV schedule should be complied with, because ARV incompliance can suppress viral load and increase ARV resistance. Routine HIV test and ARV compliance can improve body immune system thereby making HIV/AIDS status undetected.
\end{abstract}

Keywords: PLWHA; reflexive modernization; risk society; improved CD4.

\section{Introduction}

HIV (Human Immunodeficiency Virus) and AIDS (Acquired Immune Deficiency Syndrome) has been global emergency. About 35 million people living with HIV and 19 million people do not recognize their positive HIV status [1]. In the Asian area, HIV prevalence rate within society is largely still low, $<1 \%$, but in Thailand and North India. About 350,000 people were newly infected with HIV in 2012 in the Asia Pacific and $64 \%$ of them are males [2]. HIV/AIDS epidemic is problematic in Indonesia as the 5th state with most HIV/AIDS risk in Asia. The report on new HIV case increases over years since it was reported firstly (in 1987). The highest jump of 10,315 cases occurred in 2016 compared with that in 2015. Considering the data originating from HIV/AIDS Information System and IMS (SIHA) of Disease Prevention and Overcoming Directorate General, there are $57.580 \mathrm{HIV} /$ AIDS cases: $48.300 \mathrm{HIV}$ and 9.280 AIDS cases [3]. Meanwhile, there are 2,857 HIV/AIDS cases in Surakarta in the period of 2005 - December 2018: 974 HIV, 1,883 AIDS, and 701 deaths.

People with HIV/AIDS (PLWHA) use Highly Active Antiretroviral Therapy (HAART) to inhibit HIV virus replication, thereby improving their body immunity and inhibiting opportunistic infection [4]. However, in some states, ARV has not been available adequately, and even single, double, and triple dose-ARV has not been available $[5,6]$. PLWHA having made a decision to undertake ARV therapy means taking commitment, challenge and opportunity to change [4, 7]. It includes benefit, effect, and side effect (risk) of ARV therapy, like lengthening life expectancy, improving quality of life, preventing HIV/AIDS transmission from mother to child, increasing the number of people undertaking VCT, increasing the society's concern with an individual taking a test, improving PLWHA's productivity; and enabling the health worker to treat PLWHA more successfully, thereby more motivated to work [8]. However, all of these are affected by their compliance with ARV therapy as a commitment and sustainable behavior. This behavior is the product of interaction process between PLWHA and counselor, and sometimes they may not comply with ARV therapy rule because of the complex problem including disease burden due to HIV-infection measured using Disability-Adjusted Life Years (DALY) [6, 9-13].

The advantage of the compliance with ARV therapy is the reduced virus replication and the destruction of CD4 cell, the prevention of virus resistance, the increase of immune development and the inhibited disease progressiveness. The compliance rate of $95 \%$ can lead to virology success, particularly a protease inhibitor regimen. If compliance decreases, virus proliferation increased dramatically. The compliance rate of less than

\footnotetext{
* Corresponding author: argyodemartoto fisip@staff.uns.ac.id
} 
95\% will show virology failure, the detection of virus proliferation. So the PLWHA's physical/medical risk is associated with viral load affecting AIDS progressiveness, meaning that there is a relationship between CD4 with health and quality of life [14].

The risk is basically based on social construction and differences between an individual and another. Understanding, perception, and response to risk are corresponding to social context [15]. HIV/AIDS is associated with death; PLWHA are considered as the ones going to die immediately, identical with those punished by God with an unhealed disease, and criminals and frightening others, thereby should be avoided. PLWHA as the risk society in this postmodern era are the ones having known how to deal with uncertain conditions corresponding to their creativity and ability to mitigate and to deal with the risk occurring independently. Science, experience, and technology are actually paradoxical in nature because they can be the cause of and the solution to the risk all at once. The attempt to dealing with uncertainty in postmodern society is dialectic in nature or reflexive modernization, a process of changing individuals and institutions in responding to the risky and uncertain conditions $[16,17]$. Members of the society have a variety of coping and adapting mechanisms during their first HIV/AIDS diagnosis [25]. Some HIV/AIDS survivors live healthily thereby successful in their carrier and can survive in their lives. This research aims to explore the reflexivity of HIV/AIDS survivors as the risk society in maintaining their quality of life.

\section{Method}

\subsection{Research Design and Location}

This qualitative research with a descriptive phenomenological approach included intuiting, analyzing, and describing the behavior of HIV/AIDS survivors (still alive PLWHA/AIDS) as a risk society in both beginning and advanced stages [19-23]. This research was conducted in Surakarta, as HIV/AIDS survivors in Surakarta have been affiliated with Solo Plus PSG. In addition, they have opened their status to their family, workplace, and society. Those speaking up volitionally will get much more attention from the community than a clinician or non-PLWHA doing so.

\subsection{Data Source}

Key informants in this study were Program Manager of Surakarta AIDS Commission (A1) and Head of Solo Plus PSG (A2) knowing the existence of and facilitating the PLWHAs.

Ten (10) main informants qualified the criteria: HIV/AIDS survivors, undertaking ARV therapy for at least 3 months due to side effect of ARV maximally occurring in the 3rd-4th months, not on drug abstinence, and willing to be informant volitionally, and capable of revealing experience with their reflexivity as risk society in maintaining their quality of life [24].. They were 2248 years old, living in Surakarta (B1, B2, B3, B4, B5, B6, B7, B8, B9, and B10). Seven of them were graduated from Senior High School (B1, B3, B5, B6, B7, $\mathrm{B} 8$, and B10), 2 from undergraduate school (B2 and B4) and 1 from graduate school (B9). They have varying jobs: 3 employees (B2, B4, and B9), 5 entrepreneurs (B1, B5, B6, B8, and B10), 1 working in service sector (B3), and 1 not working (B7). Three survivors have not gotten married (B4, B8, and B9) and 7 have gotten married (B1, B2, B3, B5, B6, B7, and B10). All of them have undertaking ARV therapy for more than 6 months, but $2 \mathrm{HIV} / \mathrm{AIDS}$ survivors (B5 and B10) have been dropped out last year for 3 months, and they restarted their ARV therapy 9 months ago. ARV combination is commonly used: 4 using neviral and efavirens, 2 using staviral (stavudine) and efavirens, 2 using neviral, duviral, and efavirens, and 4 using neviral (neviraphine) and duviral (zidovudine and lamivudine) therapy. Methadone maintenance therapy has been undertaken by B5 and B10 for $2-3$ years. Eight survivors have received ARV and ARV consultation in Dr. Moewardi Hospital of Surakarta (B1, B2, B3, B4, B6, B7, B8, and B9), and 2 in Public Health Center of Manahan, Surakarta (B5 and B10).

Supporting informants consisted of NGOs caring about AIDS coming from Surakarta, including Director of SPK HAM Surakarta (C1), a clinician in Dr. Moewardi Hospital of Surakarta (C2), VCT counselor and psychologist in Public Health Center of Manahan, Surakarta (C3), and 2 People Affected by HIV/AIDS (PABHA) coming from Surakarta (C4 and C5).

\subsection{Technique of Collecting Data}

The author was united totally with the reflexivity of HIV/AIDS survivors as a risk society in maintaining their quality of life by studying a variety of literature. In the process of collecting data, the author became an instrument of collecting data and listened to the description given by HIV/ADIS survivors during an interview, and studied the data of their experience that has been transcribed and studied repeatedly. Then, he identified the essence of such an experience phenomenon by exploring the relationship between certain elements and the phenomenon. Finally, he communicated and gave written description on critical element or essence described separately from the context of the relationship between one and another based on their experience $[25,26]$.

\subsection{Data Validity}

Data validity or trustworthiness was tested by confirming the result of information acquired in the study with different data sources (informants). The author identified the operational application of trustworthiness, including credibility, dependability, confirmability, and transferability [21, 27]. 


\subsection{Data Analysis}

The transcription collected was the result of the interview using open-ended in-depth interview and field note as the result of observation. The author has read the field note and transcription repeatedly, thereby could understand the data well [28]. Collaizi's phenomenological method was selected to analyze the data, starting with a literature study about Beck's risk society theory and the result of studies related to the reflexivity of HIV/AIDS survivors as the risk society in dealing with medical risk. The author conducted an interview and organized the field note during the interview; read repeatedly the transcription organized based on in-depth interview and field note; selected the meaningful note related to the objective of research; organized category by keywords existing in the statement into preliminary categorization table; organized table of theme outlines categorizing the theme into sub-theme, theme, and theme group; wrote the theme of research results to HIV/AIDS survivors; and organized a final description on individual experience in the form of research findings [28, 29].

\subsection{Ethical Clearance}

The five rights of informants have been fulfilled: selfdetermination, privacy and dignity, denial, right to fair management, and the right to get protection from discomfort and loss. Consensual decision making or an informed consent approach was taken to fulfill the five rights [30-32].

\section{Result}

\subsection{ARV, its side effect, and medical risk}

C2 stated that the administration of ARV was adjusted with CD4 number and clinical stage of PLWHA. Generally, PLWHA was given ARV combination, for example, duviral constituting the combination of zidovudine and lamivudine, or of stavudine and efavirens. It is consistent with the Standard Operating Procedure for antiretroviral therapy. Meanwhile, C2 stated that the administration of ARV therapy could result in side effect (physical/medical risk). The side effects achieved maximum effect on the third and fourth months. The type of ARV drug and side effect includes abacavir (hypersensitivity reaction, meaning PLWHA developing fever, reddish skin, and even limp, nausea, vomit, loud breath); Didanosine (pancreatitis, peripheral neuropathy, nausea, diarrhea, lactate acidosis followed by hepatic steatosis); lumifudine (a little side effect, lactate acidosis followed hepatic steatosis); Lipoatrophy, sidofudine (ZDV, ACT) (Anemia, neutropenia, gastrointestinal intolerance, headache, insomnia, myopathy, lactate acidosis, followed with hepatic steatosis); Nephirapine (Hepatitis, life-threatening, hepatoxic); and Efavirenz (nervous system symptom; somnolence, insomnia, confusion, agitation, increased transaminase level, reddish). These medical risks are encountered by HIV/AIDS survivors.

Meanwhile, C3 stated that PLWHA they d ealt with generally develop side effects of ARV therapy such as anemia, impaired central nervous system, hepatoxic, nephroliatisis, metabolic disorder, and teratogenesis. B1, B3, B6, B7, and B8, B11 stated that they encounter different effects of baseline-dose ARV and double-dose ARV uses, including light life burden and high quality of life but on the other hand encountering severe physical side effect. B7 and B9 revealed that they develop blackish skin when their CD4 level is $50 / \mathrm{ml}$, but after 3month ARV therapy, their blackish skin disappears. B7 said that her CD4 level increases from 210 to 560 and their viral load becomes undetectable. B9 argued that actually the one still having CD4 value of $>200$ cell/mm3 during HIV diagnosis can be said in a good condition. Although physically his/her health condition is still good, he/she should take medication (ARV) immediately to manage his/his health in long term.

Similarly, the CD4 value of B1, B5, B6, and B10 returns to the normal level following ARV consumption. B7 and B9 stated that ARV made their body fit, body condition and weight increase by $\pm 7 \mathrm{~kg}$. It makes them more self-confident, their emotions more controlled and stable, and doing activity naturally like eating, sleeping, and taking a rest regularly, dealing with household, and working. Meanwhile, B2, B4, and B8 argued that the side effect of ARV includes nausea, vomit, and skin itchiness and reddishness. B14 consuming abacavir develops these symptoms. Nausea and vomit effect makes them eating difficultly in the morning. Heartburn is felt during nausea and vomit in the morning. The food consumed in the morning will finally get out due to nausea. PLWHA retain nausea from waking up at 5.00 to 09.00 a.m. to avoid vomit, B3 sometimes consumes liquid meal needing no mastication like juice or milk. C4 argued that there is a relationship between stress-induced depression and incompliance with ARV therapy, thereby can speed the opportunistic infection incidence, so that treatment and medication costs increase. The quick development of HIV into AIDS is closely related to heavy life burdens, denial of coping, high cortisol serum level, and low social support.

C3 dealing with ILWHA in Public Health Center of Manahan Surakarta stated that Methadone Maintenance Therapy program improves physical and psychological health, such as improving hepatitis medication as the complication for ILWHA, and reducing the adverse effect of illicit drugs and substance, contributing to the decreased mortality and morbidity rates, and preventing infectious disease from occurring. Meanwhile, C2 stated that several PLWHAs develop skin reddishness and itchiness called Steven-Johnson symptoms as the response to ARV. On average, this hypersensitive reaction occurs in the first week of ARV therapy implementation. If not managed well, this symptom will be getting worse, called sarcoidosis and tattoo intolerance. Nausea symptom is the side effect of ARV, but it can indicate the drug discontinuation as well. B5 and $\mathrm{B} 10$ develop this after ceasing ARV consumption as they were tempted again to use injected drug. They are 
grateful for neither developing infection nor influenza, but only fatigue.

$\mathrm{C} 2$ added that nevirapine, efavirenz, and ritonavir can reduce methadone concentration through cytochromeP450 (CYP3A4) induction, and generate significant drug discontinuation symptom. Drug discontinuation symptoms usually occur on the days-4 to 8 after beginning ARV therapy. Drug discontinuation symptoms likely occurring in PLWHA attending methadone maintenance therapy program and starting ARV therapy are heat, sweat, hypersecretion, nausea, diarrhea, colic abdomen, rhinorrhea, lacrimation, headache, tremor, and anxiety. B5 and B10 (ILWHA) experience these symptoms. Therefore, the analgesic administration to ILWHA undertaking ARV during methadone therapy is important, aiming to manage acute and chronic pain.

Essentially, the largest enemy of PLWHA, according to B2, is not HIV virus but fear and afraid dominating their soul. Fear and anxiety inhibit healing process as we focus on resisting the anxiety inside our heart and mind rather than fighting against HIV. B5 and B10 ever stopping from using ARV therapy feel low quality of life, and even have had suicide ideation due to a high life burden. A1, A2, and $\mathrm{C} 1$ stated that the HIV problem and the one living with it are still considered negatively by most Indonesian people. Therefore, family's role and support to PLWHA are very important to make them remaining to have spirit and expectation, to be able and willing to do the correct stage of subsequent life sustainability, in order to make their life higher in quality.

\subsection{Reflexivity on medical risk}

B3, B6, B7, and B9 develop blackish skin before attending ARV therapy. The blackish skin is very itchy, leading them to keep scratching it. There is indeed a significant relationship between CD4 numbers in plasma with a variety of clinical manifestations, one of which is candidiasis. However, C3 said that undertaking ARV therapy is beneficial to remove candidiasis and cough. Opportunistic infections can disappear along with the increased CD4 value and the decreased viral load in ARV therapy. B5 stated that having undertaken ARV therapy, CD4-number increases to $560 / \mathrm{ml}$ and viral load becomes undetectable. It can also be encountered by HIV/AIDS survivors such as B3. B3 is a HIV-infected housewife aged 37 years. She was 32 years when undertaking HIV test. Meanwhile, the HIV status of her child and husband is negative. Having consumed ARV, CD4 development is very good, and she is still working actively. Meanwhile, B7 is a HIV-infected man aged 40 years. He was 34 years when undertaking HIV test. Meanwhile, the HIV status of his 2 children and wife is negative. He has a history of hepatitis disease and renal disorder. Having consumed ARV, his CD4 development is good and he still working actively as an entrepreneur.

During undertaking ARV therapy, generally HIV/AIDS survivors feel fitter, develop weight gain, and have stable body condition. It enables them to undertake their daily life confidently and more functionally. It means that PLWHA follows the regular living pattern and play their role, and their emotion becomes stable. In addition, opened communication between PLWHA and health worker is very desirable and food is a factor to achieve maximum pharmacokinetic of ARV. Health worker should monitor PLWHA's eating pattern, because it is closely related to the compliance with ARV consumption, in addition to $95 \%$ of schedule to be complied with, as PLWHA's incompliance with ARV therapy, viewed from the schedule and pharmacokinetic, can reduce viral load suppression and can increase ARV resistance $[9,33,34]$.

C5 said that PLWHA also needs information and nutrition counselling to improve their body immunity and to resist infection. PLWHA should consume a meal according to their needs and taste. For example, PLWHA with Hepatitis $\mathrm{C}$ and $\mathrm{B}$ complication should consume hepatitis diet, with 2000-3000 calorie/day. The detail of calorie amount includes 300-400 g carbohydrate, 1-2 $\mathrm{kg} / \mathrm{kg} \mathrm{BW} /$ day protein, and adequate fat amount [35]. The source of protein the PLWHA consume should have high biological value, including milk, meat, and egg. Vitamin $\mathrm{K}$ deficiency occurs as well due to malabsorption in gastrointestinal tract and decreased ability to absorb the fat-dissolved vitamin. Vitamins A, B-complex, C, and $\mathrm{K}$ and folic acid supplements should be administrated to fulfill PLWHA's need. PLWHA develop nausea thereby disrupting food consumption in the morning. The often but small food portion should be given to suffice the nutrient intake.

$\mathrm{C} 2$ stated that an individual in critical illness condition, like B4, is indicated to be positive HIV with very low CD4, 32 cell/mm3. B4's condition can be said as belonging to acute phase, very vulnerable physically to various diseases. In this situation (ARV) drug administration immediately is the most prudent measure. Positive mind condition highly supports medical treatment. Any healing forms, either medically or mentally, has their distinctive position with their own role, because actually healing is the product of our mind (mentality). So, if we think that it will be healthy with ARV drug, the health will be obtained, and vice versa.

In his preoccupation with catering on PLWHA, C5 explained that "Think that ARV will treat HIV and will not damage our physique. When PLWHA believes that ARV will make them healthy and relieve their illness, they will get what they want, health. So the health we dream of will be brought into reality if it is based on our mind first, thinking of being healthy rather than sick. Medically healing method and mind should run synergistically and support each other for HIV healing".

Pros and cons still occur as long as the paradigm of food supplement use are still treated as a drug. For HIV case, medical treatment with ARV is the primary one, meaning that it is cannot be replaced with a supplement. More consultation with a clinician is a wise choice so that the use of health supplement supports the primary treatment (ARV). C2 said that PLWHA should understand the overview of health supplementation's contribution to medication process, and to be critical thereby capable of deciding what supplement is 
necessary or what supplement is unnecessary. They should also make more consultation with a clinician. C2 added that PLWHAs' condition is not always the same, therefore consult more with a clinician, and be wise and thinking well in choosing supplement. A natural journey of human life with healthy condition is actually a natural process needing no supplement, meaning that with the decreased activity in his old age human being does not mineral level as high as that needed when he was young. Similarly, PLWHA has physical tenacity different from the healthy ones do.

It is confirmed by $\mathrm{C} 3$ stating that the objective of supplementation is to help the body reach optimum nutrition level, if it is gotten inadequately from the food consumed. A supplement is consumed based on human body's need. Similarly, PLWHA should choose a supplement that can improve their body immunity and if possible, inhibit the virus proliferation process in the body. C3 gave an example indicating that consuming supplement containing omega-3 source contained in fish should take into account the heavy metal contamination factor and marine pollution during the fish's life process. Consuming supplements containing calcium is highly desirable for bone density in the present and in old age later. However, it will be in vain if people also consume carbohydrate and any sugar food, as it will inhibit the calcium absorbing process in the body

\section{Discussion}

In Indonesia, HIV/AIDs problem and its patients are still underestimated. There is still discrimination due to very poor understanding and knowledge of HIV. However, some HIV/AIDS survivors can reflect more in-depth on what they have experienced as well as the process. In Indonesia, a large number of PLWHAs can pass through the process of opposing HIV, survive, and be healthy now. Despite PLWHA, they remain to live healthily. The reflexivity of physical, psychological, and social risks is their learning process and submissiveness during undertaking ARV therapy [15-17]. ARV consumption means giving them the opportunity of working, because HAART is advantageous as it improves the health that can contribute to productivity.

Learning process includes the benefit of ARV therapy to HIV/AIDS survivors, side effect, compliance, and virus resistance, and ARV interaction can result in drug discontinuation symptom [36-38]. Learning process is continuous in nature because HIV/AIDS survivors are dynamic human beings so that both internal and external factors affecting their life dynamic should be taken into account. Internal factor includes symptom severity, psychiatric disease or depression, severe side effect, varying regimen, no compatibility of regimen to patients' lifestyle, and eating pattern. The external factor to be taken account is the poor understanding of the patients' dynamic. So dynamism can affect HIV/AIDS survivors' compliance with ARV therapy [8, 39]. In addition, medical risk due to the side effect of ARV and drug discontinuation symptom should be observed, as it can lower the pharmacokinetic of ARV [40].
PLWHAs facing various risks remain to keep their quality of life by dealing with and even anticipating them. HIV/AIDS survivors have reflexivity on those risks. PLWHA undertaking ARV therapy considers it as a learning process, meaning that they should think repeatedly of deciding to attend the therapy and to undertake it submissively due to their past mistake. Attending ARV therapy should be thought of repeatedly as it is a lifetime therapy. They make a submission by consuming ARV in the morning and evening just like consuming vitamin.

Any forms of reflexivity play their own role. When HIV/AIDS survivors can follow the process and undertake it well, undertake the stages correctly, sometimes they forget or do not realize that they are PLWHA. Even they do not realize that they have accepted what has been the preliminary decision they have made, being healthy and cured. It is true to B9 who has a CD4 value more than 1000 cell $/ \mathrm{mm} 3,2$ children and a wife with HIV-negative. It is just like B4's belief that he creates a positive situation in order to always live happily and to laugh in order to improve his body immunity. Meanwhile, B10 treating his health disorder leading to HIV by undertaking HIV test so that ARV medication can be implemented immediately. It is because essentially the diseases encountered like skin disorder, weight loss, and prolonged influenza are the result of decreased immunity system in PLWHA. The reflexivity leads the CD4 of HIV/AIDS survivors to increase over years, the HIV/AIDS status to be undetectable, and the quality of life to be wellmaintained.

\section{Conclusion}

During learning process in initiating and undertaking ARV therapy, dynamic internal and external factors of HIV/AIDS survivors should be taken into account. The presence of expectation construction can maintain compliance with ARV therapy. Information on HIV, nutrition service and ARV service integrated into number and prevention of ARV's side effect is very important to mitigate physical, psychological, and social risks because many risks can inhibit the compliance with ARV. The medical risk the HIV/AIDS survivors encounter can be managed using reflexivity so that the quality of life can be maintained well.

This work was supported by grants from the Ministry of Research, Technology and Higher Education, Indonesia Number: 089/SP2H/LT/DRPM/2018. The author declare that they have no competing interests.

\section{References}

1. UNAIDS, The Gap Report, UNAIDS Geneva Switzerland (2014)

2. UNAIDS, HIV in Asia and the Pasific.UNAIDS Report 2013, UNAIDS Bangkok Thailand (2013) 
3. Info DATIN Pusat Data dan Informasi Kementerian Kesehatan Republik Indonesia, Situasi Umum HIV/AIDS dan Tes HIV.Tes HIV dan HIV PositifBerdasarkan Laporan SIHA Tahun 20132017, Info DATIN Pusat Data dan Informasi Kementerian Kesehatan Republik Indonesia, Jakarta (2018)

4. M. Malta, M.L. Petersen, S. Clair, F. Freitas, F.I. Bastos, Adherence to Antiretroviral Therapy: A Qualitative Study With Physicians From Riodejaneiro, Cad Saude Publica 21(5), 1424-1432 (2005)

5. C.A. Kozinetz, R. Matusa, A. Cazacu, The Burden of Pediatric HIV/AIDS in Constanta, Romania: A Cross-Sectional Study, BMC Infectious Diseases 1, 7 (2001)

6. H.C.G. e Silvaa, J. da Silva, J. Traebert, Burden of AIDS in a Brazilian State, J. Infect. Public Health 7(4), 308-313 (2014)

7. P. Voon, K. Hayashi, L.T.K. Kaplan, P. Suwannawong, E. Wood, T. Kerr. High Prevalence of Syringe Lending Among HIV-Positive People Who Inject Drugs in Bangkok, Thailand, Harm Reduction Journal 12(16), 12-16 (2015).

8. FHI, WHO, I-TECH, Participant Manual for the WHO Basic ART Clinical Training Course, Geneva Switzerland WHO (2003)

9. B. Achappa, D. Madi, U. Bhaskaran, J.T. Ramapuram, S. Rao, S. Mahalingam, Adherence to Antiretroviral Therapy Among People Living with $H I V$, N. Am. J. Med. Sci. 5(3), 220-223 (2013)

10. GBD DALYs and HALE Collaborators. Global, Regional, and National Disability-Adjusted LifeYears (Dalys) for 333 Diseases and Injuries and Healthy Life Expectancy (HALE) for 195 Countries and Territories 1990-2016: A Systematic Analysis for the Global Burden of Disease Study 2016, GHM 390, 10100 : 1260-1344 (2017)

11. C. Stein, Global Burden of Disease (GBD) Approach and the Use of Disability-Adjusted Life Years (DALY) at the World Health Organization (WHO), Geneva Switzerland WHO (2018)

12. O.T. Hall, R.P. McGrath, M.D Peterson, E.H. Chadd, M.J. DeVivo, A. Heinemann, C.Z. Kalpakjian, The Burden of Traumatic Spinal Cord Injury in the United States: Disability-Adjusted Life Years, Arch. Phys. Med. Rehab. 100(1), 95-100 (2019)

13. A. Bórquez, J.V. Guanira, P. Revill, P. Caballero, C.F. Cáceres, The Impact and Cost-Effectiveness of Combined HIV Prevention Scenarios Among Transgender Women Sex-Workers in Lima Peru: A Mathematical Modelling Study, The Lancet Public Health 4(3), e127-e136 (2019)

14. D.L. Paterson, S.S. Swindells, J.A. Mohr, M. Brester, E.N. Vergis, C.L. Squier, M.M. Wagener, N.H. Singh, Adherence to Protease Inhibitor Therapy and Outcomes in Patients with HIV Infection, Ann. Intern. Med. 133(1), 21-30 (2000)

15. R. York, E.A. Rosa, T. Dietz, Footprints on the Earth: The Environmental Consequences of Modernity, Am. Sociol. Rev. 68(2), 279-300 (2003)
16. U. Beck. Risk Society: Towards a New Modernity, Sage Publication London (1992)

17. R. Inglehart. Sociological Theories of Modernization, International Encyclopedia of the Social \& Behavioral Sciences, 9965-9971 (2001)

18. E. Chapman, Conceptualisation for the Body of People Living with HIV: Issue of Touch and Contamination, Sociology of Health and Illness 22(6), 840-857 (2000)

19. H. Spiegelberg, The Pure Phenomenology of Edmund Husserl (1859-1938). The Phenomenological Movement A Historical Introduction Student Edition, 69-165 (1965)

20. J.W. Cresswel, Qualitative Inquiry and Research Design: Choosin Among Five Traditions, Sage Publications Inc, Thousands Oaks (1998)

21. H.J. Streubert, D.R. Carpenter, Qualitative Research in Nursing: Advancint the Humanistic Imperative 2nd Edition, Philadelphia Lippincott (1999)

22. J.A. Fain, Reading, Understanding, and Applying Nursing Research 5th Edition, F.A.Davis Company Philadelphia (2017)

23. D.F. Polit, C.T. Beck, Nursing Research: Principles and Methods. 7th Edition, Lippincott William \& Wilkins Philadelphia (2004)

24. I. Holloway, S. Wheeler, Qualitative Research in Nursing and Healthcare $3^{\text {rd }}$ Edition, WileyBlackwell Science Ltd London (2013)

25. J.M. Morse, P-A, Field. Nursing Research: The Application of Qualitative Approaches 2nd ed, Sage Publications Inc. California Thousand Oaks (1996)

26. N.K. Denzin, Y.S. Lincoln, Collecting and Interpretating Qualitative Materials, Sage Publications Inc. Thousand Oaks (2003)

27. E.G. Guba, Y.S. Lincoln, Paradigmatic, Controversies, Contradictions, and Emergencies Confluences, Handbook of qualitative research, edited by Norman. K. Denzin \& Yvonna. S. Lincoln (Eds.), 105-117. (Sage Publications, Inc, Thousand Oaks, CA, US, 2005)

28. P.F. Colaizzi, Psychological Research as the Phenomenologist Views: Existential Phenomenological Alternatives for Psychology, Oxford University Press New York, 48-71 (1978)

29. R. Morrow, A. Rodriguez. N. King, Colaizzi's Descriptive Phenomenological Method, The Psychologist 28(8), 643-644 (2015)

30. R. Andorno, Global bioethics at UNESCO: In defense of the Universal Declaration on Bioethics and Human Rights, J. Med. Ethics. 33(3), 150-154 (2007)

31. W. Walker, Ethical Considerations in Phenomenological Research, Nurse Researcher. 14(3), 36-45 (2007)

32. A.N. Association, Code of Ethics for Nurses with Interpretive Statements, Silver Spring MD (2014)

33. WHO, HIV/AIDS Treatment and Care, Geneva Switzerland WHO (2004)

34. N. Higgins, B.S. Zingman, J. Slish, R.C. Reichman, M.A. Fischl, B. Gripshover, Factors Associated 
with Altered Pharmacokinetics in Substance Users and Non-Substance Users Receiving Lopinavir and Atazanavir, Am. J. Addict. 16(6), 488-94 (2007)

35. S.G. Dudek, Nutrition Hand Book for Nursing Practice, Lippincott Raven-publisher, Philadelphia (1997)

36. F. Mesquita, I. Winarso, I.I. Atmosukarto, B. Eka, L. Nevendorff, A. Rahmah, P. Handoyo, P. Anastasia, R. Angela, Public Health the Leading Force of the Indonesian Response to the HIV/AIDS Crisis Among People Who Inject Drugs, Harm Reduction Journal 4(9) (2007)

37. D.P. Goldman, Y. Bao, Effective HIV Treatment and the Employment of HIV+ Adults, Health Serv. Res. 39(6), 1691-1712 (2004)

38. W. Friedman, Antiretroviral Drug Access and Behavior Change, J. Dev. Econ. 135, 392-411 (2018)

39. WHO, European Framework to Decrease the Burden of $T B / H I V$, Geneva Switzerland WHO (2003)

40. WHO, Patient Monitoring Guidelines for HIV Care and Antiretroviral Therapy (ART), Geneva Switzerland WHO (2006) 